\title{
A Multilevel Model Approach for Investigating Individual Accident Characteristics and Neighborhood Environment Characteristics Affecting Pedestrian-Vehicle Crashes
}

\author{
Seunghoon Park ${ }^{1, *(1)}$ and Dongwon Ko ${ }^{2}$ \\ 1 Department of Urban Planning, Keimyung University, Daegu 42601, Korea \\ 2 Gyeonggi Research Institute, Suwon 16207, Korea; dw2774@naver.com \\ * Correspondence: parksh1541@kmu.ac.kr; Tel.: +82-53-580-5048
}

Received: 1 April 2020; Accepted: 26 April 2020; Published: 29 April 2020

check for updates

\begin{abstract}
Walking is the most basic movement of humans and the most fundamental mode of transportation. To promote walking, it is necessary to create a safe environment for pedestrians. However, pedestrian-vehicle crashes still remain relatively high in South Korea. This study employs a multilevel model to examine the differences between the lower-level individual characteristics of pedestrian crashes and the upper-level neighborhood environmental characteristics in Seoul, South Korea. The main results of this study are as follows. The individual characteristics of pedestrian-vehicle crashes are better at explaining pedestrian injury severity than built environment characteristics at the neighborhood level. Older pedestrians and drivers suffer more severe pedestrian injuries. Larger vehicles such as trucks and vans are more likely to result in a high severity of pedestrian injuries. Pedestrian injuries increase during inclement weather and at night. The severity of pedestrian injuries is lower at intersections and crosswalks without traffic signals than at crosswalks and intersections with traffic signals. Finally, school zones and silver zones, which are representative policies for pedestrian safety in South Korea, fail to play a significant role in reducing the severity of pedestrian injuries. The results of this study can guide policymakers and planners when making decisions on how to build neighborhoods that are safer for pedestrians.
\end{abstract}

Keywords: pedestrian-vehicle crashes; built environment; multilevel model; pedestrian injury severity

\section{Introduction}

From the 1970s, rapid industrialization caused a considerable portion of the South Korean population to migrate to Seoul, its capital city, to seek jobs opportunities, thereby accelerating the process of urbanization of the country [1]; however, a rapid increase in the urban population caused a serious housing crisis [2-4]. In response to this crisis, the South Korean government permitted the rapid construction of residential buildings over the recent decades, thereby leading to reckless land development in the suburbs surrounding Seoul; this development resulted in urban sprawl that forced residents to rely on cars. Consequently, pedestrian-vehicle crashes have increased within South Korea's automobile-oriented society [5].

Hence, to reduce pedestrian-vehicle crashes, the South Korean government has adopted a transportation paradigm that attempts to make its automobile-oriented society safer for pedestrians. It is important for societies to ensure safe walking environments for its citizens, as pedestrians are much more likely to suffer serious injuries from a traffic accident than drivers [6-9]. In South Korea, various studies have suggested methods for reducing pedestrian-vehicle crashes [10-16]. Choi et al. [11] insisted on the need to focus on the silver zones for the safety of the elderly. Kwon and Park [14] 
emphasized the importance of the child pedestrian safety around elementary schools. However, the level of such crashes in South Korea remains high.

In 2016, South Korea had one of the highest rates of fatalities per capita for road traffic accidents among Organization for Economic Co-operation and Development (OECD) countries [17]. In short, a pedestrian's risk of death or injury is much higher than in other countries. Despite the fact that the number of road fatalities has decreased steadily over the past decade due to improved pedestrian safety policies, the share of pedestrian fatalities among the total number of road fatalities has increased from $35 \%$ to $38 \%$ [18]; this percentage is much higher than the OECD average of $20 \%$ [17].

This study examines individual and neighborhood environmental characteristics that affect the severity of pedestrian-vehicle crashes in Seoul, South Korea. Particularly, this study employs a multilevel model to account for the differences between the lower-level individual characteristics and the upper-level neighborhood environmental characteristics of pedestrian-vehicle crashes. Our findings are significant, as they will allow for more informed discussions on pedestrian safety.

\section{Literature Review}

\subsection{Individual Characteristics of Pedestrian-Vehicle Crashes}

Recent research on pedestrian-vehicle crashes can be largely categorized into studies on the frequency of crashes and studies on the severity of pedestrians' injuries [19-29]. To create a safe environment for pedestrians, it is important to reduce the frequency of crashes. However, it is equally important to prevent serious pedestrian injuries resulting from pedestrian-vehicle crashes.

The majority of research has focused on particular characteristics of pedestrian crashes that influence the severity of pedestrian injuries. These characteristics have been mainly explored on the basis of three types of characteristics; namely, driver, pedestrian, and crash event characteristics.

Regarding driver characteristics, most studies have revealed that pedestrian injuries are likely to be more severe in pedestrian crashes involving a male driver [15,23,30-32]. Moreover, the severity of pedestrians' injuries has been increased with the increase in the age of the driver [23,31]. However, Pour-Rouholamin et al. [33] analyzed the severity of pedestrian injuries in Illinois, U.S., by comparing drivers under the age of 24 years to those over the age of 65 years and found that these two groups can demonstrate very different results: drivers under the age of 24 years are more likely to cause severe pedestrian injuries compared with those in the age group of 25 to 64 years; however, drivers over the age of 65 years are more likely to cause no/possible pedestrian injuries compared with those in the age group of 25 to 64 years. Choi et al. [34] has also analyzed instances of severe pedestrian injury involving novice drivers and found that less driving experience correlates to more severe pedestrian injuries.

Regarding pedestrian characteristics, some studies have revealed that female pedestrians are more likely to be injured in pedestrian-vehicle crashes than male pedestrians $[15,32,35]$. However, Ulfarsson et al. [30] stated that male pedestrians are more likely to suffer serious injuries while analyzing the North Carolina regions. Meanwhile, some studies have examined pedestrian accidents on the basis of age $[33,36,37]$. Most studies have demonstrated that pedestrian injuries are more severe among elderly pedestrians. In particular, Pour-Rouholamin et al.'s study [33] of children-involved crashes shows that pedestrian injury is more serious when children are younger. Chen and Fan [38] also noted that the age of a pedestrian has an effect on the crash fatality rates, but not on other severity levels. In addition, Haleem et al. [39] studied the severity of pedestrian injuries at signalized and non-signalized intersections in Florida, U.S., and stated that very old people involved in crashes at both signalized and non-signalized intersections had similar levels of severe injuries; however, middle-aged individuals were more likely to suffer serious injuries at non-signalized intersections. They argued that it is necessary to not only understand the behavioral characteristics of drivers and pedestrians, but also strengthen traffic regulations to reduce pedestrian fatalities.

Regarding crash event characteristics, the weather has also been found to affect the severity of pedestrian injuries. The severity of pedestrian injuries has been shown to increase in inclement 
weather $[15,29,32,40,41]$. However, some studies have stated contradictory results, claiming that the severity of pedestrian injuries decreases in inclement weather [42,43]. In particular, Yu [44] has argued that both drivers and pedestrians are likely to refrain from going out when the weather is bad, resulting in less serious injuries; Michalaki et al. [43] and Quddus et al. [45] have also claimed that the severity of pedestrian injuries increases under dryer road conditions. Additionally, Aziz et al. [46] also studied factors affecting the severity of pedestrian-vehicle crashes in New York, revealing that pedestrian injuries are more serious under wet road conditions. Lee and Lee [47] demonstrated that weather and road surface conditions differently influence the severity of pedestrian injuries. Based on these studies, it can be concluded that inclement weather may affect the vision of drivers and lengthen the vehicle stopping distances. However, inclement weather may also lead to reduced vehicle speed and generally play a significant role in reducing exposure for pedestrians, as people are less likely to go out walking in bad weather.

Brightness and darkness also have different effects on the severity of pedestrian injuries. Previous studies have emphasized that poor visibility and darkness increase the severity of pedestrian injuries [41,42,48]. However, Quddus et al. [45] also noted that the severity of pedestrian injuries sometimes decreases when it is dark.

Crash event characteristics, such as time of the day [43,49], crashes at intersections or crosswalks [15,47], and a driver's level of intoxication [37,50], have been considered as determinants influencing the severity of pedestrian injuries. Meanwhile, Zhang et al. [37] exhibited that drunk driving results in more serious pedestrian injuries and argued that punishments for drunk driving should be more stringent.

\subsection{Neighborhood Environmental Characteristics of Pedestrian-Vehicle Crashes}

Various studies have considered neighborhood environmental characteristics that may affect the severity of pedestrian injuries, such as demographic factors, road features, land use, and land development indicators [46,51-56].

Studies on demographic factors mainly focus on the age of the drivers and the pedestrians and population density by age $[32,36,48,55-57]$. Some studies have demonstrated that populations with a higher ratio of residents of 65 years and older have more serious pedestrian injuries [32,48,57]. Clifton and Kreamer-Fults [56] showed that pedestrian injuries are more serious in pedestrian-vehicle crashes occurring near schools in densely populated neighborhoods with a large population of children between 5 and 15 years. This finding corresponds with Bae and Park [15]. However, Kim et al. [35] also studied the injury severity of pedestrian crashes across South Korea by employing a hierarchically ordered model, thereby arguing that the higher the population density, the lower the severity of pedestrian injuries. When studying road accidents in Hong Kong, Sze and Wong [48] demonstrated that as the percentage of the population under the age of 15 years increases, pedestrian injuries become less serious. Similar results were reported in Narayanamoorthy et al. [55], that analyzed 285 census tracts from Manhattan, New York. Noland and Quddus [57] also reported similar findings while analyzing the severity of pedestrian injuries in 11 UK regions. Therefore, depending on the study sites and the spatial units, demographic factors have affected pedestrian road fatalities in an inconsistent manner. Even when analyzing the same study site and spatial unit, results may vary depending on the age groups.

Regarding road characteristics, studies have shown that narrow road width and low road density have a negative effect on the severity of pedestrian injuries $[32,35,47,56]$. These findings have implied that countries with wider roads and higher road density experience more crashes involving pedestrians. However, Kim et al. [35] examined types of roads in more detail and found that the severity of pedestrian injuries was less on roads with a width of less than $3 \mathrm{~m}$. Therefore, in future studies, it is necessary to subdivide the effects of pedestrian risk exposure on the basis of the road width. In general, crosswalks reduce the severity of pedestrian injuries [15,33,39,58]. However, Tay et al. [32] also studied the severity of pedestrian injuries by using a multinomial logit model and found that crosswalks 
increase the severity of pedestrian injuries. Unlike crosswalks, intersections increased the severity of pedestrian injuries in several studies $[19,29,32,48]$. In addition, other studies have considered various road characteristics, such as traffic signals [33,37,49], speed limits [59-61], and signs [19,50], as factors influencing the severity of pedestrian injuries.

In addition to demographics and road characteristics, land use characteristics have also been considered in studies on pedestrian injury severity [23,55,62-64]. Narayanamoorthy et al. [55] analyzed 285 census tracts in New York and noted that residential, commercial, and industrial areas have a similar level of severity of pedestrian injuries, regardless of land use type. Kwon and Park [14] also examined the effects of land use around elementary schools in South Korea and noted that residential areas seem to experience fewer pedestrian fatalities. Kim et al. [31] also studied the severity of pedestrian injuries in North Carolina, U.S., and found that commercial areas are likely to experience less severe pedestrian injuries. However, this finding contradicted with Narayanamoorthy et al. [55]

Development density is also related to the severity of pedestrian injuries $[14,36,47]$. Mohamed et al. [36] proved that single or double family residential land use decreases the likelihood of pedestrian fatalities in New York. Kwon and Park [14] have also studied safe routes to school in residential areas of Seoul and found that the higher the floor area ratio of the residential buildings around elementary schools, the lower the severity of pedestrian injuries. Lee and Lee [47] have indicated that the gross floor area of commercial facilities reduces the severity of pedestrian injuries. However, they also found that the gross floor area of industrial facilities increased the severity of pedestrian injuries. In addition, various neighborhood environmental factors, such as urban areas [33,38], school zones [15], and parking lots [36,40], have been studied as factors influencing the severity of pedestrian injuries.

This literature review demonstrates that various factors affect the severity of pedestrian injuries. Previous studies have shown that the individual characteristics of the drivers and the pedestrians affect the severity of injuries in pedestrian-vehicle crashes. Additionally, studies have also shown that neighborhood environmental characteristics affect pedestrian-vehicle crashes differently, depending on the study sites and the spatial units. However, in South Korea, little research has been conducted on the severity of pedestrian injuries that consider both the individual characteristics of crashes and the built environment of neighborhoods.

Therefore, this study employs a multilevel model to identify factors influencing the severity of pedestrian injuries, by considering not only the neighborhood environmental characteristics, but also individual crash characteristics.

\section{Data and Model}

\subsection{Data}

This study used pedestrian-vehicle crash data from 2015 to 2017 provided by Korea's Traffic Accident Analysis System [65]. In all, 24,827 pedestrian-vehicle crashes were geocoded through the GIS program (Figure 1). Through a literature review, the lower-level individual characteristics of crashes were divided into three categories; namely, pedestrian, driver, and crash event characteristics. The individual characteristics of crashes include pedestrian age and sex, driver age and sex, vehicle types, weather, crash at intersections, crash at crosswalks, and time variables. 


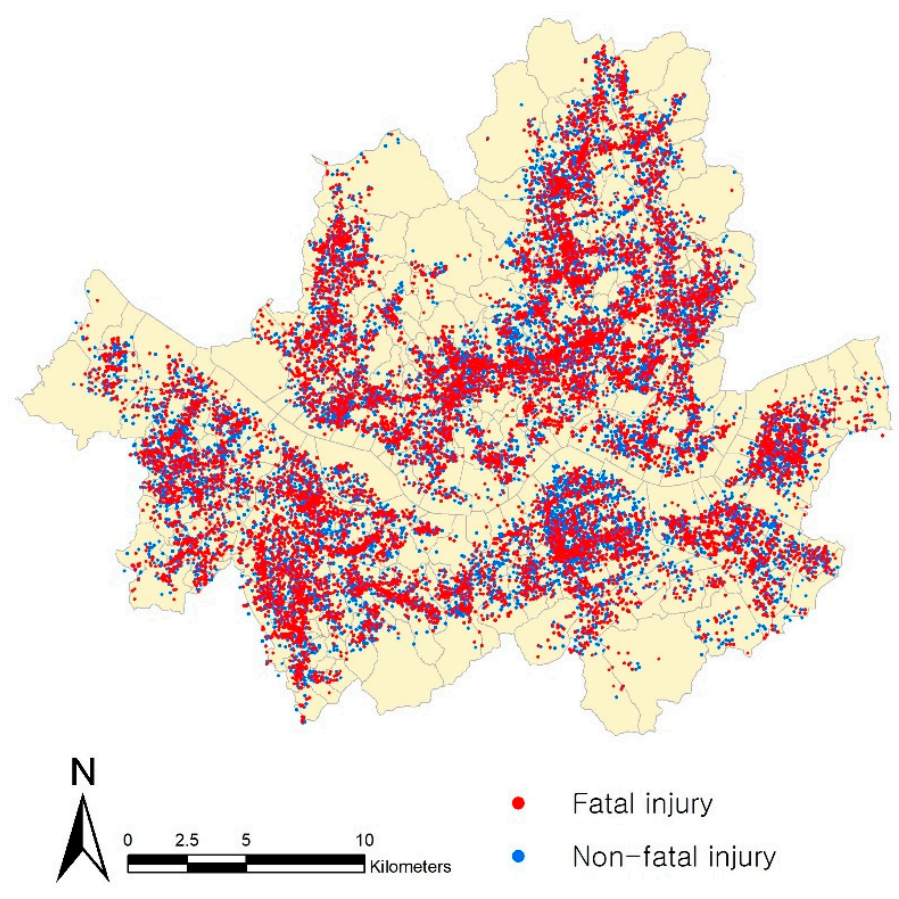

Figure 1. Spatial distribution of pedestrian-vehicle crashes in Seoul.

For upper-level neighborhood environmental characteristics, built environment characteristics of 424 administrative districts in Seoul were measured. The neighborhood-level attributes were divided into five characteristics; namely, roads, land use, land development, safety zones, and population demographics.

For road characteristics, road humps, neighborhood streets, main roads, signalized crosswalks, non-signalized crosswalks, signalized intersections, non-signalized intersections, and posted speed were considered. These variables were provided by the Seoul Open Data Plaza [66] and the Road Name Address Guidance System [67]. Land use data provided by the Seoul Urban Planning Portal were used to examine residential and commercial areas [68]. In addition to two-dimensional land use, building data provided by the National Spatial Data Infrastructure Portal were used to measure the average gross floor area of residential buildings and the average gross floor area of commercial buildings to explore the effects of land development on pedestrian-vehicle crashes [69]. In addition, data provided by the Open Data Portal and the Seoul Open Data Plaza were used to evaluate the impact of school zones and silver zones, which represent central transportation policies for pedestrian safety in South Korea [66,70]. Finally, demographic data provided by the Korean Statistical Information Service were used to examine general population density and the population density of those under 15 years and those over 65 years [71].

\subsection{Estimated Stage of Multilevel Binomial Logistic Model}

Individuals are influenced by the characteristics of the built environment in which they live. In addition, individuals belong to larger groups that share common characteristics that distinguish individuals of that group from individuals of another group [72]. A multilevel model is a statistical analysis method for analyzing data with a hierarchical structure composed of individuals and groups [73]. This multilevel model can account for the effects of interactions between levels and the direct effects of variables measured at different levels [74]. This study aims to identify factors that affect the severity of pedestrian injuries, by examining individual characteristics of crashes as lower-level factors and neighborhood environmental characteristics as higher-level factors. The estimation process of a multilevel linear model is given below [35,73-76]. 
Step one sets up an intercept-only model. This model is mainly referred to as a null model. The Equation (1) of step one is expressed in the following manner:

$$
Y_{i j}=\gamma_{00}+u_{0 j}+e_{i j}
$$

A null model does not include any explanatory variable and includes only error terms at the upper and lower levels. In a null model, $\gamma_{00}$ is the overall mean of the sample. $u_{0 j}$ is the difference of the mean between neighborhoods. $e_{i j}$ is the difference between individual accidents.

Step two sets up a model that applies the individual characteristics affecting a dependent variable as explanatory variables. Equation (2) of step two is expressed in the following manner:

$$
Y_{i j}=\gamma_{00}+\gamma_{p 0} X_{p i j}+u_{0 j}+e_{i j}
$$

$X_{p i j}$ is an explanatory variable applied at a lower level. At the step two, the intercept and the slope coefficient are assumed to vary across neighborhoods (upper level). Step two estimates the influence of explanatory variables that affect the variance of a dependent variable at the lower level. In addition, the change in variance of the lower level and the upper level is estimated by incorporating explanatory variables into the lower level.

Step three expands the model by adding neighborhood environmental characteristics as explanatory variables at the neighborhood level, which is the upper level. The Equation (3) of step three is expressed in the following manner:

$$
Y_{i j}=\gamma_{00}+\gamma_{p 0} X_{p i j}+\gamma_{0 q} Z_{q j}+u_{0 j}+e_{i j}
$$

$Z_{q j}$ is the explanatory variable applied at the upper level. If $Y_{i j}$ is binary, a hierarchical binomial logistic model is appropriate. At step three, the intercept is assumed to vary across neighborhoods, but the slope coefficient is assumed not to vary across the neighborhood (upper level).

The Equation (4) of the multilevel binomial logistic model used to determine the severity of pedestrian injuries in this study is expressed in the following manner:

$$
\log \left(\frac{p i j}{1-p_{i j}}\right)=\gamma_{00}+\sum_{q=1}^{Q} \gamma_{0 q} X_{q j}+\sum_{p=1}^{P} \gamma_{p 0} Z_{p i j}+u_{0 j}
$$

$P_{i j}$ is the pedestrian severity of injury. $\frac{p i j}{1-p_{i j}}$ is the odds ratio of a fatal injury. $\gamma_{00}$ is the intercept. $X_{q j}$ is the explanatory variable of individual characteristics of crashes, which include the characteristics of drivers, pedestrians, and crash events. $Z_{p j i}$ is the explanatory variable of neighborhood environmental characteristics. $u_{0 j}$ is the random effect of neighborhood environmental characteristics, which include the characteristics of roads, land use, land development, safety zones, and population characteristics.

\section{Results and Discussion}

\subsection{Results of Descriptive Statistic Analysis}

Table 1 depicts a descriptive analysis identifying factors that affect the severity of pedestrian injuries in Seoul. In this study, the severity of pedestrian injuries as a dependent variable has an average value of about 0.43 ; this means that about $43 \%$ of pedestrian-vehicle crashes in Seoul result in a fatal injury. In other words, pedestrian safety in Seoul is very poor. 
Table 1. Descriptive statistics.

\begin{tabular}{|c|c|c|c|c|c|c|}
\hline Level & \multicolumn{2}{|c|}{ Variables } & Definition & Unit & Mean & Std. Dev. \\
\hline \multicolumn{3}{|c|}{ Severity of pedestrian injury } & $\begin{array}{l}\text { Severity of pedestrian injury } \\
(1=\text { Fatal injury, } 0=\text { Other })\end{array}$ & $\begin{array}{l}\text { Binomial } \\
\text { logit }\end{array}$ & 0.43 & 0.49 \\
\hline \multirow{9}{*}{$\begin{array}{l}\text { Individual } \\
\text { characteristics } \\
\text { (Lower level) }\end{array}$} & \multirow{2}{*}{$\begin{array}{l}\text { Pedestrian } \\
\text { characteristics }\end{array}$} & Pedestrian age & Pedestrian age & Number & 45.72 & 20.79 \\
\hline & & Pedestrian sex & $\begin{array}{c}\text { Pedestrian sex } \\
(1=\text { Male, } 0=\text { Female })\end{array}$ & Dummy & 0.51 & 0.50 \\
\hline & \multirow{2}{*}{$\begin{array}{c}\text { Driver } \\
\text { characteristics }\end{array}$} & Driver age & Driver age & Number & 49.26 & 13.38 \\
\hline & & Driver sex & $\begin{array}{c}\text { Driver sex } \\
(1=\text { Male }, 0=\text { Female })\end{array}$ & Dummy & 0.81 & 0.39 \\
\hline & \multirow{5}{*}{$\begin{array}{l}\text { Crash event } \\
\text { characteristics }\end{array}$} & Vehicles & $\begin{array}{c}\text { Vehicle types }(1=\text { Truck or Van, } \\
0=\text { Passenger car })\end{array}$ & Dummy & 0.22 & 0.41 \\
\hline & & Weather & $\begin{array}{c}\text { Weather condition } \\
(1=\text { Inclement, } 0 \text { = Other })\end{array}$ & Dummy & 0.12 & 0.33 \\
\hline & & Time & $\begin{array}{c}\text { Time }(1=\text { Night }(18-06) \\
0=\text { Other })\end{array}$ & Dummy & 0.42 & 0.49 \\
\hline & & $\begin{array}{l}\text { Crash at } \\
\text { intersection }\end{array}$ & $\begin{array}{c}\text { Pedestrian-vehicle crash at } \\
\text { intersection }(1=\text { At intersection, } \\
0=\text { Other })\end{array}$ & Dummy & 0.32 & 0.46 \\
\hline & & $\begin{array}{l}\text { Crash at } \\
\text { crosswalk }\end{array}$ & $\begin{array}{l}\text { Pedestrian-vehicle crash at } \\
\text { crosswalk }(1=\text { At crosswalk, } \\
0=\text { Other })\end{array}$ & Dummy & 0.08 & 0.27 \\
\hline \multirow{17}{*}{$\begin{array}{l}\text { Neighborhood } \\
\text { environmental } \\
\text { characteristics } \\
\text { (Upper level) }\end{array}$} & \multirow{8}{*}{$\begin{array}{c}\text { Road } \\
\text { characteristics }\end{array}$} & Road humps & Number of humps per $\mathrm{km}^{2}$ & Density & 21.52 & 18.31 \\
\hline & & $\begin{array}{l}\text { Neighborhood } \\
\text { streets }\end{array}$ & $\begin{array}{c}\text { Proportion of } \\
\text { neighborhood streets }\end{array}$ & Ratio & 61.98 & 16.30 \\
\hline & & $\begin{array}{l}\text { Main } \\
\text { roads }\end{array}$ & Proportion of main roads & Ratio & 21.56 & 13.12 \\
\hline & & $\begin{array}{l}\text { Signalized } \\
\text { crosswalks }\end{array}$ & $\begin{array}{l}\text { Number of signalized } \\
\text { crosswalks per } \mathrm{km}^{2}\end{array}$ & Density & 25.37 & 13.49 \\
\hline & & $\begin{array}{l}\text { Non-signalized } \\
\text { crosswalks }\end{array}$ & $\begin{array}{l}\text { Number of non- signalized } \\
\text { crosswalks per } \mathrm{km}^{2}\end{array}$ & Density & 52.11 & 29.77 \\
\hline & & $\begin{array}{l}\text { Signalized } \\
\text { intersections }\end{array}$ & $\begin{array}{l}\text { Number of signalized } \\
\text { intersections per } \mathrm{km}^{2}\end{array}$ & Density & 47.50 & 28.04 \\
\hline & & $\begin{array}{l}\text { Non-signalized } \\
\text { intersection }\end{array}$ & $\begin{array}{l}\text { Number of non- signalized } \\
\text { intersections per } \mathrm{km}^{2}\end{array}$ & Density & 172.60 & 108.84 \\
\hline & & Posted speed & Average posted speed & $\operatorname{Avg}(\mathrm{km} / \mathrm{h})$ & 50.48 & 4.41 \\
\hline & \multirow{2}{*}{$\begin{array}{c}\text { Land use } \\
\text { characteristics }\end{array}$} & Residential areas & Proportion of residential areas & Ratio & 70.62 & 28.47 \\
\hline & & $\begin{array}{l}\text { Commercial } \\
\text { areas }\end{array}$ & Proportion of commercial areas & Ratio & 7.92 & 15.08 \\
\hline & \multirow{2}{*}{$\begin{array}{l}\text { Land } \\
\text { development } \\
\text { characteristics }\end{array}$} & $\begin{array}{l}\text { Gross floor area } \\
\text { of housing } \\
\text { buildings }\end{array}$ & $\begin{array}{l}\text { Average gross floor area of } \\
\text { housing buildings }\end{array}$ & $\operatorname{Avg}\left(m^{2}\right)$ & 1423.06 & 2685.19 \\
\hline & & $\begin{array}{l}\text { Gross floor area } \\
\text { of commercial } \\
\text { buildings }\end{array}$ & $\begin{array}{l}\text { Average gross floor area of } \\
\text { commercial buildings }\end{array}$ & $\operatorname{Avg}\left(m^{2}\right)$ & 1566.66 & 2758.04 \\
\hline & \multirow{2}{*}{$\begin{array}{l}\text { Safety zone } \\
\text { characteristics }\end{array}$} & School zones & $\begin{array}{l}\text { Number of school } \\
\text { zones per } \mathrm{km}^{2}\end{array}$ & Density & 3.67 & 2.63 \\
\hline & & Silver zones & $\begin{array}{l}\text { Number of silver } \\
\text { zones per } \mathrm{km}^{2}\end{array}$ & Density & 0.24 & 0.51 \\
\hline & \multirow{3}{*}{$\begin{array}{l}\text { Population } \\
\text { characteristics }\end{array}$} & Population & Population per $\mathrm{km}^{2}$ & Density & $24,705.37$ & $16,803.56$ \\
\hline & & Under 15 years & $\begin{array}{l}\text { Population under } 15 \text { years old } \\
\text { per } \mathrm{km}^{2}\end{array}$ & Density & 2701.67 & 2168.02 \\
\hline & & Over 65 years & $\begin{array}{l}\text { Population over } 65 \text { years old } \\
\text { per } \mathrm{km}^{2}\end{array}$ & Density & 3067.75 & 2170.37 \\
\hline
\end{tabular}

The average ages of a pedestrian and a driver involved in a pedestrian-vehicle crash are 46 and 49 years, respectively. Men and women are involved in pedestrian crashes at similar rates; males account for about $51 \%$ of all pedestrians involved in pedestrian-vehicle crashes. However, 
males account for about $81 \%$ of all drivers in pedestrian-vehicle crashes. Despite the increase in the number of female drivers in South Korea each year, men are consistently involved in more pedestrian-vehicle crashes than women. Trucks and vans are involved in $22 \%$ of all pedestrian-vehicle crashes. In addition, approximately $12 \%$ and $42 \%$ of pedestrian-vehicle accidents occurred during inclement weather and at night, respectively, in Seoul. Approximately $32 \%$ of pedestrian traffic accidents occurred at intersections, while about $8 \%$ of pedestrian-vehicle crashes occurred at crosswalks.

Regarding built environment characteristics, neighborhoods have an average of 22 road humps. Neighborhood streets, which are largely used for pedestrian traffic, account for about $62 \%$ of all roads. Main roads, which are mainly used for vehicle traffic, account for about $22 \%$. Neighborhoods have an average of 25 and 52 signalized and non-signalized crosswalks, respectively, and neighborhoods have an average of 48 and 173 signalized and non-signalized intersections, respectively. Non-signalized intersections are three times more likely than signalized intersections to result in pedestrian injury. The average posted speed of neighborhoods in Seoul is approximately $50.48 \mathrm{~km} / \mathrm{h}$. On average, about $71 \%$ of neighborhoods are residential, while commercial areas are less common, i.e., about $8 \%$. The average gross floor area of residential buildings in a neighborhood, which is an index of residential development, is about $1423 \mathrm{~m}^{2}$, and the average gross floor area of commercial buildings in a neighborhood, which is an index of commercial development, is about $1566 \mathrm{~m}^{2}$. Each neighborhood has an average of four school zones, which are a part of South Korea's Safe Routes to School program. Despite South Korea being a rapidly aging society, on average, each neighborhood has only 0.24 silver zones, which are areas meant to provide safe walking environments for the elderly. Finally, the average population density of neighborhoods in Seoul is about 24,705 people per $\mathrm{km}^{2}$. The average population density for those under 15 is about 2702 people per $\mathrm{km}^{2}$, and the average population density for those above 65 is about 3068 people per $\mathrm{km}^{2}$.

\subsection{Discussion of Findings}

Table 2 presents the results after applying a multilevel binomial logistic model. Model 1 is an unconditional model that does not include independent variables. This model only calculates the explanatory power of the probabilities of a fatal injury from the variance data of the individual characteristics (lower level) and neighborhood environmental characteristics (upper level) before the independent variables are included. Model 2 includes only individual characteristics (lower level). Model 3 includes both individual characteristics (lower level) and neighborhood environmental characteristics (upper level). The intraclass correlation coefficient (ICC) values represent the hierarchical explanatory power of both the individual and the neighborhood environmental characteristics [74,75]. The ICC values are $0.023,0.018$, and 0.040 for models one, two, and three, respectively; these findings indicate that the individual characteristics of pedestrian crashes play a significant role in explaining the severity of pedestrian injuries in Seoul. Contrastingly, the impact of characteristics of the built environment on the severity of pedestrian-vehicle crashes in Seoul is relatively low. Therefore, these findings suggest that more attention should be paid to safety awareness and traffic regulations through education and awareness campaigns, to reduce the severity of pedestrian-vehicle crashes. In addition, behavioral problems do not necessarily imply the need for behavioral solutions; for example, in the case of preventing drivers from falling asleep, a reasonable number of rest stops and rumble strips need to be constructed. 
Table 2. Results of multilevel binomial logistic model.

\begin{tabular}{|c|c|c|c|c|c|c|c|c|c|c|c|}
\hline \multirow{2}{*}{\multicolumn{2}{|c|}{ Classification }} & \multirow[b]{2}{*}{ Variables } & \multicolumn{3}{|c|}{ Model 1} & \multicolumn{3}{|c|}{ Model 2} & \multicolumn{3}{|c|}{ Model 3} \\
\hline & & & Coefficient & Std. Error & $\begin{array}{l}\text { Odds } \\
\text { Ratio }\end{array}$ & Coefficient & Std. Error & $\begin{array}{l}\text { Odds } \\
\text { Ratio }\end{array}$ & Coefficient & Std. Error & $\begin{array}{l}\text { Odds } \\
\text { Ratio }\end{array}$ \\
\hline \multicolumn{3}{|c|}{ Intercept } & $-0.201^{* * *}$ & 0.019 & 0.817 & $-1.613^{* * *}$ & 0.069 & 0.199 & $-1.608^{* * *}$ & 0.291 & 0.200 \\
\hline \multirow{9}{*}{$\begin{array}{c}\text { Individual } \\
\text { characteristics } \\
\text { (Lower level) }\end{array}$} & \multirow{2}{*}{$\begin{array}{c}\text { Pedestrian } \\
\text { characteristics }\end{array}$} & Pedestrian age & & & & $0.023^{* * *}$ & 0.000 & 1.023 & $0.024^{* * *}$ & 0.000 & 1.024 \\
\hline & & Pedestrian sex & & & & $-0.288^{* * *}$ & 0.027 & 0.749 & $-0.268^{* * *}$ & 0.029 & 0.764 \\
\hline & \multirow{2}{*}{$\begin{array}{c}\text { Driver } \\
\text { characteristics }\end{array}$} & Driver age & & & & $0.003^{* * *}$ & 0.001 & 1.003 & $0.003^{* * *}$ & 0.001 & 1.003 \\
\hline & & Driver sex & & & & 0.001 & 0.036 & 1.001 & 0.007 & 0.039 & 1.007 \\
\hline & \multirow{5}{*}{$\begin{array}{l}\text { Crash event } \\
\text { characteristics }\end{array}$} & Vehicles & & & & $0.133^{* * *}$ & 0.033 & 1.142 & $0.132 * * *$ & 0.036 & 1.141 \\
\hline & & Weather & & & & $0.119^{* * *}$ & 0.040 & 1.126 & $0.125^{* * *}$ & 0.043 & 1.043 \\
\hline & & Time & & & & $0.278^{* * *}$ & 0.028 & 1.320 & $0.286^{* * *}$ & 0.033 & 1.331 \\
\hline & & Crash at intersection & & & & $0.216^{* * * *}$ & 0.029 & 1.241 & $0.247^{* * *}$ & 0.031 & 1.280 \\
\hline & & Crash at crosswalk & & & & $0.517^{* * *}$ & 0.050 & 1.676 & $0.521^{* * *}$ & 0.055 & 1.683 \\
\hline \multirow{17}{*}{$\begin{array}{l}\text { Neighborhood } \\
\text { environmental } \\
\text { characteristics } \\
\text { (Upper level) }\end{array}$} & \multirow{8}{*}{$\begin{array}{c}\text { Road } \\
\text { characteristics }\end{array}$} & Road humps & & & & & & & $0.003^{* * *}$ & 0.001 & 1.003 \\
\hline & & Neighborhood streets & & & & & & & $-0.003 *$ & 0.002 & 0.997 \\
\hline & & Main roads & & & & & & & -0.002 & 0.002 & 0.998 \\
\hline & & Signalized crosswalks & & & & & & & -0.002 & 0.000 & 0.998 \\
\hline & & Non-signalized crosswalks & & & & & & & $-0.002 * * *$ & 0.000 & 0.998 \\
\hline & & Signalized intersections & & & & & & & $0.002 *$ & 0.001 & 1.002 \\
\hline & & Non-signalized intersections & & & & & & & $-0.000 * * *$ & 0.000 & 1.000 \\
\hline & & Posted speed & & & & & & & 0.006 & 0.004 & 1.006 \\
\hline & \multirow{2}{*}{$\begin{array}{c}\text { Land use } \\
\text { characteristics }\end{array}$} & Residential areas & & & & & & & -0.000 & 0.000 & 1.000 \\
\hline & & Commercial areas & & & & & & & 0.000 & 0.001 & 1.000 \\
\hline & \multirow{2}{*}{$\begin{array}{l}\text { Land development } \\
\text { characteristics }\end{array}$} & Gross floor area of housing buildings & & & & & & & 0.000 & 0.000 & 1.000 \\
\hline & & Gross floor area of commercial buildings & & & & & & & 0.000 & 0.000 & 1.000 \\
\hline & \multirow{2}{*}{$\begin{array}{l}\text { Safety zone } \\
\text { characteristics }\end{array}$} & School zones & & & & & & & -0.000 & 0.008 & 1.000 \\
\hline & & Silver zones & & & & & & & 0.013 & 0.034 & 1.013 \\
\hline & \multirow{3}{*}{$\begin{array}{l}\text { Population } \\
\text { characteristics }\end{array}$} & Population & & & & & & & -0.000 & 0.000 & 1.000 \\
\hline & & Under 15 years & & & & & & & 0.000 & 0.000 & 1.000 \\
\hline & & Over 65 years & & & & & & & 0.000 & 0.000 & 1.000 \\
\hline \multirow{2}{*}{\multicolumn{3}{|c|}{$\begin{array}{c}\text { Random Intercept } \\
\text { ICC }\end{array}$}} & \multicolumn{3}{|c|}{0.0776} & \multicolumn{3}{|c|}{0.0590} & \multicolumn{3}{|c|}{0.2683} \\
\hline & & & \multirow{2}{*}{\multicolumn{3}{|c|}{$\begin{array}{c}0.023 \\
33816.3\end{array}$}} & \multicolumn{3}{|c|}{0.018} & \multicolumn{3}{|c|}{0.040} \\
\hline \multicolumn{3}{|c|}{ Deviance } & & & & \multirow{2}{*}{\multicolumn{3}{|c|}{$\begin{array}{c}32088.4 \\
24826\end{array}$}} & & 32033.8 & \\
\hline \multicolumn{3}{|c|}{ Number of observations } & \multicolumn{3}{|c|}{24826} & & & & & 24826 & \\
\hline
\end{tabular}

${ }^{* * *} p<0.01, * p<0.1$ 
However, it cannot be said that the characteristics of the built environment of neighborhoods have no influence on the severity of pedestrian-vehicle crashes. More informed urban planning, urban design, and transportation policies can reduce the likelihood of pedestrian crashes and pedestrian fatalities, by improving neighborhood environments. Hence, it is necessary to not only better educate drivers and pedestrians and strengthen laws, but also to improve the built environments of neighborhoods for pedestrian safety.

An analysis of the lower-level individual characteristics reveals that all variables except a driver's sex have an influence on the severity of pedestrian injuries. Female pedestrians are more likely to be involved in a pedestrian-vehicle crash than men; this finding is consistent with the results of previous studies $[15,32,35]$.

Similar to previous studies [32,35-38], it was shown that the older the pedestrian, the more fatal the accident. Older people are less active, and therefore they are physically weak. Demetriades et al. [77] conducted a study on the relationship of age on injury type and severity and demonstrated that the risk of severe pedestrian injury is higher among elderly pedestrians. South Korea has a rapidly aging population, and therefore reducing injuries to elderly pedestrians urgently needs to be addressed.

Additionally, the severity of pedestrian injuries tends to be more serious as drivers get older; this finding also agrees with earlier studies [15,78].

Jang et al. [79] stated that elderly drivers have a higher severity of pedestrian injuries due to a lack of judgment, slower reaction speed, and poor vehicle control when accidents occur. Therefore, as the population ages, it is necessary to increase the visibility of road signs and install better streetlights to improve nighttime visibility. There also prevails a need for specialized traffic safety programs targeted toward the elderly, such as the silver mark system. A driver's license renewal system for the elderly is also advisable [80]. In addition, there prevails a need for various incentive systems, such as providing vouchers to elderly drivers in return for relinquishing their driver's licenses voluntarily.

Similar to previous studies, the severity of pedestrian-vehicle crashes were higher among trucks and vans $[23,31,36-39]$. Therefore, special training and education must be included in truck and van driving tests, to strengthen pedestrian safety.

As shown in Table 1, the incidence of pedestrian-vehicle crashes in inclement weather is only $12 \%$. However, pedestrian injuries suffered in inclement weather are more serious; these findings agree with previous studies [15,20,32,39-41]. In contrast to these findings, Yu [44] has studied pedestrian-vehicle crashes in 140 census tracts in Austin, Texas and found that pedestrians and drivers tend to stay at home during inclement weather, reducing the severity of pedestrian injuries. Therefore, in the case of inclement weather, smart transportation facilities incorporating networked devices need to be developed, to make it easier for drivers to recognize pedestrians from afar.

The results of the model also show that pedestrian-vehicle crashes are more likely to occur at night. Mohamed et al. [36] demonstrated a similar result when studying New York and Montreal. He asserts that, at night, both drivers and pedestrians do not have enough time to react in the event of a sudden crash, due to low visibility. Hence, it is necessary to improve overall nighttime visibility on roads, particularly in places where crashes frequently occur.

Pedestrian-vehicle crashes occurring at crosswalks or intersections are more likely to result in serious injury; this finding agrees with previous studies $[15,29,47,48]$. Intersections and crosswalks are generally spots where drivers concentrate on driving safety. Nevertheless, the high severity of pedestrian injuries occurring at intersections and crosswalks highlights the need for greater attention to pedestrian safety around intersections and crosswalks. At intersections, drivers are often distracted. Similarly, pedestrian injuries often result from a driver unable to see a pedestrian. For accidents at crosswalks, drivers may continue to drive without noticing that the traffic signal has changed. Contrastingly, pedestrians may fail to see oncoming traffic or ignore a signal while jaywalking. Therefore, both drivers and pedestrians need to be educated about how to drive and walk safely around intersections and crosswalks. However, a few studies state that crashes at intersections have a lower 
injury severity compared to other pedestrian-vehicle crashes $[36,81]$. These studies assert that traffic at intersections is more complicated, and therefore drivers may voluntarily slow down their vehicles.

Interestingly, among various neighborhood environmental characteristics, land use, land development, the prevalence of safety zones, and population demographics are not statistically significant for explaining the severity of pedestrian injuries. In fact, only road characteristics play a significant role in explaining the association between the built environment and injury severity. As noted above, it seems that lower-level individual characteristics have a greater influence on the severity of pedestrian injuries than the built environment. However, it is important to consider the contextual effects of each characteristic, even if there is no statistical significance for some built environment characteristics.

Among road characteristics, road humps have been shown to increase the severity of pedestrian-vehicle crashes. However, previous studies have shown that road humps can effectively reduce the vehicle speed, and therefore, the frequency and severity of pedestrian-vehicle crashes $[82,83]$. According to a survey on the safety of road humps by the Korea Consumer Agency, more than $60 \%$ of humps did not meet installation standards in 2014 [84]. Therefore, improperly installed and maintained road humps that do not meet the installation standards may threaten the safety of the pedestrians and the drivers in South Korea.

There is no statistically significant correlation between the severity of pedestrian injuries and road hierarchy. Neighborhood streets mainly used by pedestrians appear to be poorly associated with the severity of pedestrian injuries at a level of $p<0.1$; this finding is in agreement with previous studies that indicate that neighborhood streets experience a lower number of crashes that result in severe pedestrian injuries $[32,35,47]$. However, main roads, which are primarily used for vehicle traffic, are not statically associated with a higher incidence of severe pedestrian injuries. Even more interestingly, posted speed also does not show a statistical significance. However, several studies have revealed that posted speed is likely to increase the severity of pedestrian injury [15,38,39,43,47]; this counterintuitive finding implies that, in these situations, crashes occur because of increased speed rather than road hierarchy or posted speed. In addition, the existence and condition of sidewalks where pedestrians can walk safely also needs to be considered as an important factor.

This study has revealed new insights into pedestrian-vehicle accidents at crosswalks and intersections. The majority of previous studies have not studied signalized crosswalks and non-signalized crosswalks separately $[15,33,39,58]$. Instead, these studies have simply indicated that crosswalks play a role in reducing pedestrian injuries. This study divided crosswalks into signalized crosswalks and non-signalized crosswalks and found that, in relation to predicting the severity of pedestrian injury, the presence of a signalized crosswalks did not produce a statistically significant difference, whereas non-signalized crosswalks were observed to increase the incidence of pedestrian-vehicle crashes. In other words, crosswalks without traffic signals were found to be safer for pedestrians than crosswalks with traffic signals.

A similar result was found for intersections. Several studies have shown that intersections generally experience a high number of severe pedestrian-vehicle crashes [19,29,32,48]. However, these studies do not consider differences between intersections with and without traffic signals. In this study, the intersection variable was divided into signalized and non-signalized intersections as well as crosswalks. Interestingly, the study revealed that pedestrian-vehicle crashes that occur at intersections without traffic signals result in less severe pedestrian injuries than pedestrian crashes at intersections with traffic signals. Various factors, such as the vehicle speed, traffic volume, and the number of lanes, can cause significant differences between signalized intersections and non-signalized ones. A possible explanation for the behavior of drivers and pedestrians is that both tend to be more cautious of avoiding crashes at intersections and crosswalks without traffic signals than at intersections and crosswalks with traffic signals. A possible conclusion that can be drawn from these findings is that traffic signals may not contribute significantly to pedestrian safety. Previous studies that examined the relationship between traffic signals and pedestrian-vehicle crashes have yielded conflicting results. Kim et al. [23] 
and Kim et al. [31] noted that traffic signals improve pedestrian safety, while Celik and Oktay [49] emphasized that traffic signals have a negative impact on pedestrian safety. This study also finds that traffic signals do not necessarily guarantee improved pedestrian safety. This aspect indicates the need for both the drivers and the pedestrians to comply with traffic signals, particularly in South Korea. Hence, there prevails a need to educate the drivers and the pedestrians to ensure that they comply with traffic rules.

The land use characteristics of certain areas in Seoul, whether residential or commercial, were not significantly associated with the severity of pedestrian injuries. A possible explanation for this finding is that residential and commercial areas are not as clearly demarcated as in North America due to the distinctive characteristics of land use in South Korea. Indeed, land use in Seoul is mixed, with commercial facilities such as convenience stores and restaurants commonly appearing within residential areas.

In addition to a two-dimensional concept of land use, this study also examined the characteristics of land development, which refers to the degree of actual development in a three-dimensional setting. Both the average gross floor area of residential buildings and the average gross floor area of commercial buildings had no correlation with the severity of pedestrian injuries. However, higher land development, whether commercial or residential, could correlate to more walking by residents; this aspect suggests that more pedestrians are exposed to possible collisions with vehicles on roads. Therefore, the implementation of transportation policies and strategies such as traffic calming to control traffic volume and traffic flow should be considered in areas with high residential development.

School zones and silver zones, which represent two important transportation policies for pedestrian safety in South Korea, have no statistically significant relation to pedestrian injuries. In South Korea, school zones and silver zones are designated as protection areas on roads within a radius of $300 \mathrm{~m}$. These zones are meant to protect children and the elderly [85]. In particular, school zones are related to the Safe Routes to School policy, which has mainly been studied in North America. However, both of these zones display a negative sign, despite no significance. There are a few studies on the effects of built environment characteristics around school zones on the frequency of pedestrian crashes $[14,86]$. However, there is little research on the effectiveness of school zones for the severity of pedestrian injuries. School zones in South Korea mainly involve installing and managing traffic safety facilities, such as safety fences, safety signs, and speed cameras. Therefore, there is a need for constant attention concerning the effectiveness of school zones for children to walk safely to school. In addition, it is suggested that children in South Korea need to be taught safe walking skills in kindergartens, and they should practice those skills walking to school in groups. Even the junior high students need to learn how to use the transit system and navigate other neighborhoods. Silver zones also have no statistically significant relationship with pedestrian injuries; however, they demonstrate a positive direction concerning the severity of pedestrian-vehicle crashes; this aspect suggests that silver zones have not yet been institutionalized in South Korea. School zones were first introduced in South Korea in 1995, while silver zones were first introduced in 2006. As of 2017, Seoul has 1733 and 118 school zones and silver zones, respectively [87]. In the future, in addition to school zones, there is a need for continuous attention and research on the efficacy of silver zones for the elderly, who are more vulnerable to traffic accidents.

Finally, the demographic factors according to age groups do not exhibit statistical significance. Although population density is not associated with the severity of pedestrian injury, it indicates a negative direction; this finding is in agreement with previous studies analyzing the same study area in South Korea [35]. However, a study on pedestrian crashes near public schools in Baltimore, US insists that the higher the population density, the higher the severity of pedestrian-vehicle crashes [56].

The population density of those 15 years and younger and the population density of those 65 years and older also have no statistical significance. However, they exhibit a positive direction, which is in contrast to the negative direction of the overall population density. In South Korea, people aged 15 years and younger and people aged 65 years and older are classified as vulnerable road users 
according to the Act on Promotion of Transportation [88]. This finding suggests that more attention should be given to vulnerable road users who are at risk of being injured in pedestrian-vehicle crashes.

\section{Conclusions}

Countries must provide safe walking environments to provide a high quality of life to their citizens. Therefore, it is important to reduce the frequency of pedestrian-vehicle crashes and the severity of pedestrian injuries. This study investigated built environment characteristics affecting the severity of pedestrian injuries in South Korea, a country with a high rate of pedestrian-vehicle crashes. In particular, this study examined the individual characteristics of pedestrian crashes that have not been considered in previous studies $[14,47,89,90]$. Previous studies have only examined built environment characteristics, without incorporating individual characteristics of pedestrian-vehicle crashes, and therefore, it has been difficult to identify the effect of built environment characteristics on injury severity accurately. Thus, it can be difficult to develop accurate and effective policies for ensuring pedestrian safety. This study, therefore, employed a multilevel analysis to examine the influence of lower-level individual characteristics of pedestrian crashes, alongside the upper-level built environment characteristics of neighborhoods on the severity of pedestrian injuries. The main results of this study are as follows.

First, the individual characteristics of pedestrian-vehicle crashes are better at explaining pedestrian injury severity than built environment characteristics at the neighborhood level. Therefore, the individual characteristics of pedestrian crashes must be considered in future research on pedestrian-vehicle crashes. In addition to improving the physical environment to increase pedestrian safety, policies that consider attributes of drivers, pedestrians, and crash events are needed.

Second, older pedestrians and drivers suffer more severe pedestrian injuries. Therefore, whether drivers or pedestrians, transportation safety policies and strategies to safeguard the elderly must be developed. It is necessary to expand traffic safety facilities that can ensure the safety of elderly pedestrians. For older drivers, policies that reinforce driving tests and license renewal systems, while also encouraging elderly drivers to voluntary relinquish their driver's licenses are necessary.

Third, larger vehicles such as trucks and vans are more likely to result in a high severity of pedestrian injuries. Therefore, special safe driving training should be facilitated to large vehicle drivers.

Fourth, pedestrian injuries increase during inclement weather and at night. Therefore, various pedestrian safety facilities and streetlights to increase visibility should be installed. In addition, during bad weather or at night, regulations to lower the posted speed are necessary.

Fifth, pedestrian-vehicle crashes at crosswalks and intersections result in more severe pedestrian injuries. However, the severity of pedestrian injuries is lower at intersections and crosswalks without traffic signals than at crosswalks and intersections with traffic signals. Therefore, qualitative environmental improvements around crosswalks and intersections and quantitative increases of crosswalks and intersections should be implemented, to reduce the severity of pedestrian injury. In addition, it is necessary to consider ways to install roundabouts that can reduce traffic accidents.

Finally, school zones and silver zones, which are representative policies for pedestrian safety in South Korea, fail to play a significant role in reducing the severity of pedestrian injuries. Therefore, in-depth policy development and discussions about the designation of safety zones and the installation of effective traffic safety facilities around safety zones should be implemented and held, respectively, by transportation, urban planning, and urban administration experts.

This study also had some limitations. For example, pedestrian-vehicle crashes are events that occur in open spaces and therefore possess spatial attributes. However, this study was unable to consider spatial dependence and spatial autocorrelation between pedestrian crashes. Future studies should investigate spatial heterogeneity between neighborhoods. Traffic volume and pedestrian volume may also be the contributing factors that directly or indirectly affect the severity of pedestrian injuries. However, this study fails to consider these two potential indicators because of the limitation of the acquired data. More in-depth investigations could be conducted if the necessary data were 
acquired. Nevertheless, the results of this study can guide policymakers and planners when making decisions on how to build neighborhoods that are safer for pedestrians.

Author Contributions: Conceptualization, S.P. and D.K.; methodology, S.P. and D.K.; writing-original draft preparation, S.P. and D.K.; writing - review and editing, S.P. and D.K. All authors have read and agreed to the published version of the manuscript.

Funding: This work was supported by the National Research Foundation of Korea (NRF) (No. NRF-2018R1D1A1B07050844).

Conflicts of Interest: The authors declare no conflict of interest.

\section{References}

1. Park, S.H.; Ko, D.W. Investigating the effects of the built environment on PM2. 5 and PM10: A case study of Seoul Metropolitan city, South Korea. Sustainability 2018, 10, 4552. [CrossRef]

2. Baker, E.; Lester, L. Multiple housing problems: A view through the housing niche lens. Cities 2017, 62, 146-151. [CrossRef]

3. Al-Hafith, O.; Satish, B.K.; Bradbury, S.; de Wilde, P. A systematic assessment of architectural approaches for solving the housing problem in Iraq. Front. Archit. Res. 2018, 7, 561-572. [CrossRef]

4. De Paris, S.R.; Lopes, C.N.L. Housing flexibility problem: Review of recent limitations and solutions. Front. Archit. Res. 2018, 7, 80-91. [CrossRef]

5. Park, C.; Lee, S. An Analysis of the Characteristics of Street Environment Affecting Pedestrian Accidents. J. Urban Des. Inst. Korea 2016, 17, 105-121. (In Korean)

6. Yao, S.; Loo, B.P.; Lam, W.W. Measures of activity-based pedestrian exposure to the risk of vehicle-pedestrian collisions: Space-time path vs. potential path tree methods. Accid. Anal. Prev. 2015, 75, 320-332. [CrossRef]

7. Yang, J. Review of injury biomechanics in car-pedestrian collisions. Int. J. Veh. Saf. 2005, 1, 100-117. [CrossRef]

8. Yang, J.; Otte, D. A comparison study on vehicle traffic accident and injuries of vulnerable road users in China and Germany. In Proceedings of the 20th International Technical conference on the Enhanced Safety of Vehicles, Lyon, France, 18-21 June 2017; pp. 7-417.

9. Chen, G. Road traffic safety in African countries-status, trend, contributing factors, countermeasures and challenges. Int. J. Inj. Cont. Saf. Promot. 2010, 17, 247-255. [CrossRef]

10. Choi, J.; Tay, R.; Kim, S.; Jeong, S. Behaviors of older pedestrians at crosswalks in South Korea. Accid. Anal. Prev. 2019, 127, 231-235. [CrossRef]

11. Choi, Y.; Yoon, H.; Jung, E. Do Silver Zones reduce auto-related elderly pedestrian collisions? Based on a case in Seoul, South Korea. Accid. Anal. Prev. 2018, 119, 104-113. [CrossRef] [PubMed]

12. Chung, Y.; Chang, I. How accurate is accident data in road safety research? An application of vehicle black box data regarding pedestrian-to-taxi accidents in Korea. Accid. Anal. Prev. 2015, 84, 1-8. [CrossRef] [PubMed]

13. Lee, W.K.; Lee, H.A.; Hwang, S.; Kim, H.; Lim, Y.-H.; Hong, Y.-C.; Ha, E.-H.; Park, H. A time series study on the effects of cold temperature on road traffic injuries in Seoul, Korea. Environ. Res. 2014, 132, 290-296. [CrossRef] [PubMed]

14. Kwon, J.; Park, S. A Study on the Factors Affecting Pedestrian Traffic Fatal Accidents around Elementary Schools: A Case Study of the Seoul Metropolitan City. J. Korea Plan. Assoc. 2018, 53, 57-73. (In Korean) [CrossRef]

15. Bae, M.; Park, S. The Effects of Individual and Neighborhood Environmental Characteristics on the Severity of Pedestrian Traffic Accidents in Daegu Metropolitan City. J. Korean Reg. Dev. Assoc. 2019, 31, 239-258. (In Korean)

16. Rhee, K.A.; Kim, J.K.; Lee, Y.-I.; Ulfarsson, G.F. Spatial regression analysis of traffic crashes in Seoul. Accid. Anal. Prev. 2016, 91, 190-199. [CrossRef] [PubMed]

17. Adler, M.W.; Ahrend, R. Traffic Safety in Korea. OECD Reg. Dev. Work. 2017. [CrossRef]

18. Traffic Accident Analysis System (TAAS). Available online: http://taas.koroad.or.kr/sta/acs/exs/typical.do? menuId=WEB_KMP_OVT_UAS_TAT (accessed on 16 July 2019). (In Korean) 
19. Chen, P.; Zhou, J. Effects of the built environment on automobile-involved pedestrian crash frequency and risk. J. Transp. Health 2016, 3, 448-456. [CrossRef]

20. Pulugurtha, S.S.; Sambhara, V.R. Pedestrian crash estimation models for signalized intersections. Accid. Anal. Prev. 2011, 43, 439-446. [CrossRef]

21. Wang, J.; Huang, H.; Zeng, Q. The effect of zonal factors in estimating crash risks by transportation modes: Motor vehicle, bicycle and pedestrian. Accid. Anal. Prev. 2017, 98, 223-231. [CrossRef]

22. Miranda-Moreno, L.F.; Morency, P.; El-Geneidy, A.M. The link between built environment, pedestrian activity and pedestrian-vehicle collision occurrence at signalized intersections. Accid. Anal. Prev. 2011, 43, 1624-1634. [CrossRef] [PubMed]

23. Kim, J.K.; Ulfarsson, G.F.; Shankar, V.N.; Mannering, F.L. A note on modeling pedestrian-injury severity in motor-vehicle crashes with the mixed logit model. Accid. Anal. Prev. 2010, 42, 1751-1758. [CrossRef] [PubMed]

24. Morency, P.; Gauvin, L.; Plante, C.; Fournier, M.; Morency, C. Neighborhood social inequalities in road traffic injuries: The influence of traffic volume and road design. Am. J. Public Health 2012, 102, 1112-1119. [CrossRef] [PubMed]

25. Colucci, B.; Valle, D. Characterization of Motor Vehicle-Pedestrian Fatalities in Urban Arterial Corridor; Transportation Research Board: Washington, DC, USA, 2014; pp. 14-4444.

26. Gitelman, V.; Balasha, D.; Carmel, R.; Hendel, L.; Pesahov, F. Characterization of pedestrian accidents and an examination of infrastructure measures to improve pedestrian safety in Israel. Accid. Anal. Prev. 2012, 44, 63-73. [CrossRef] [PubMed]

27. Zegeer, C.V.; Bushell, M. Pedestrian crash trends and potential countermeasures from around the world. Accid. Anal. Prev. 2012, 44, 3-11. [CrossRef]

28. Prijon, T.; Ermenc, B. Influence of alcohol intoxication of pedestrians on injuries in fatal road accidents. Forensic Sci. Int. Suppl. Ser. 2009, 1, 33-34. [CrossRef]

29. Eluru, N.; Bhat, C.R.; Hensher, D.A. A mixed generalized ordered response model for examining pedestrian and bicyclist injury severity level in traffic crashes. Accid. Anal. Prev. 2008, 40, 1033-1054. [CrossRef]

30. Ulfarsson, G.F.; Kim, S.; Booth, K.M. Analyzing fault in pedestrian-motor vehicle crashes in North Carolina. Accid. Anal. Prev. 2010, 42, 1805-1813. [CrossRef]

31. Kim, J.-K.; Ulfarsson, G.F.; Shankar, V.N.; Kim, S. Age and pedestrian injury severity in motor-vehicle crashes: A heteroskedastic logit analysis. Accid. Anal. Prev. 2008, 40, 1695-1702. [CrossRef]

32. Tay, R.; Choi, J.; Kattan, L.; Khan, A. A multinomial logit model of pedestrian-vehicle crash severity. Int. J. Sustain. Transp. 2011, 5, 233-249. [CrossRef]

33. Pour-Rouholamin, M.; Zhou, H. Investigating the risk factors associated with pedestrian injury severity in Illinois. J. Saf. Res. 2016, 57, 9-17. [CrossRef] [PubMed]

34. Choi, S.; Park, J.; Oh, C. Factors Affecting Injury Severity in Pedestrian-Vehicle Crash by Novice Driver. Korean Soc. Transp. 2011, 29, 43-51. (In Korean)

35. Kim, M.; Kho, S.Y.; Kim, D.K. Hierarchical ordered model for injury severity of pedestrian crashes in South Korea. J. Saf. Res. 2017, 61, 33-40. [CrossRef]

36. Mohamed, M.G.; Saunier, N.; Miranda-Moreno, L.F.; Ukkusuri, S.V. A clustering regression approach: A comprehensive injury severity analysis of pedestrian-vehicle crashes in New York, US and Montreal, Canada. Saf. Sci. 2013, 54, 27-37. [CrossRef]

37. Zhang, G.; Yau, K.K.; Zhang, X. Analyzing fault and severity in pedestrian-motor vehicle accidents in China. Accid. Anal. Prev. 2014, 73, 141-150. [CrossRef] [PubMed]

38. Chen, Z.; Fan, W.D. A multinomial logit model of pedestrian-vehicle crash severity in North Carolina. Int. J. Transp. Sci. Technol. 2019, 8, 43-52. [CrossRef]

39. Haleem, K.; Alluri, P.; Gan, A. Analyzing pedestrian crash injury severity at signalized and non-signalized locations. Accid. Anal. Prev. 2015, 81, 14-23. [CrossRef]

40. Clifton, K.J.; Burnier, C.V.; Akar, G. Severity of injury resulting from pedestrian-vehicle crashes: What can we learn from examining the built environment? Transp. Res. D Transp. Environ. 2009, 14, 425-436. [CrossRef]

41. Lee, C.; Abdel-Aty, M. Comprehensive analysis of vehicle-pedestrian crashes at intersections in Florida. Accid. Anal. Prev. 2005, 37, 775-786. [CrossRef]

42. Zhang, G.; Yau, K.K.; Chen, G. Risk factors associated with traffic violations and accident severity in China. Accid. Anal. Prev. 2013, 59, 18-25. [CrossRef] [PubMed] 
43. Michalaki, P.; Quddus, M.A.; Pitfield, D.; Huetson, A. Exploring the factors affecting motorway accident severity in England using the generalised ordered logistic regression model. J. Saf. Res. 2015, 55, 89-97. [CrossRef] [PubMed]

44. Yu, C.Y. Built environmental designs in promoting pedestrian safety. Sustainability 2015, 7, 9444-9460. [CrossRef]

45. Quddus, M.A.; Wang, C.; Ison, S.G. Road traffic congestion and crash severity: Econometric analysis using ordered response models. J. Transp. Eng. 2010, 136, 424-435. [CrossRef]

46. Aziz, H.A.; Ukkusuri, S.V.; Hasan, S. Exploring the determinants of pedestrian-vehicle crash severity in New York City. Accid. Anal. Prev. 2013, 50, 1298-1309. [CrossRef]

47. Lee, G.; Lee, S. An Analysis of the Factors of Pedestrian Traffic Accident by Driver's Age and Accident Severity. J. Urban Des. Inst. Korea 2016, 17, 63-80. (In Korean)

48. Sze, N.N.; Wong, S.C. Diagnostic analysis of the logistic model for pedestrian injury severity in traffic crashes. Accid. Anal. Prev. 2007, 39, 1267-1278. [CrossRef]

49. Celik, A.K.; Oktay, E. A multinomial logit analysis of risk factors influencing road traffic injury severities in the Erzurum and Kars Provinces of Turkey. Accid. Anal. Prev. 2014, 72, 66-77. [CrossRef]

50. Anastasopoulos, P.C.; Mannering, F.L. An empirical assessment of fixed and random parameter logit models using crash-and non-crash-specific injury data. Accid. Anal. Prev. 2011, 43, 1140-1147. [CrossRef]

51. Harvey, C.; Aultman-Hall, L. Urban streetscape design and crash severity. Transp. Res. Rec. 2015, $2500,1-8$. [CrossRef]

52. Ouyang, Y.; Bejleri, I. Geographic Information System-Based Community-Level Method to Evaluate the Influence of Built Environment on Traffic Crashes. Transp. Res. Rec. 2014, 2432, 124-132. [CrossRef]

53. Xu, X.; Šarić, Ž.; Zhu, F.; Babić, D. Accident severity levels and traffic signs interactions in state roads: A seemingly unrelated regression model in unbalanced panel data approach. Accid. Anal. Prev. 2018, 120, 122-129. [CrossRef] [PubMed]

54. Iranitalab, A.; Khattak, A. Comparison of four statistical and machine learning methods for crash severity prediction. Accid. Anal. Prev. 2017, 108, 27-36. [CrossRef] [PubMed]

55. Narayanamoorthy, S.; Paleti, R.; Bhat, C.R. On accommodating spatial dependence in bicycle and pedestrian injury counts by severity level. Transp. Res. Part B Method 2013, 55, 245-264. [CrossRef]

56. Clifton, K.J.; Kreamer-Fults, K. An examination of the environmental attributes associated with pedestrian-vehicular crashes near public schools. Accid. Anal. Prev. 2007, 39, 708-715. [CrossRef]

57. Noland, R.B.; Quddus, M.A. Analysis of pedestrian and bicycle casualties with regional panel data. Transp. Res. Rec. 2004, 1897, 28-33. [CrossRef]

58. Lee, H.; Lee, S. An Analysis of Associations between Neighborhood Road Networks and Pedestrian Traffic Accidents: Focused on the TAAS(2014) in Seoul, Korea. J. Korea Plan. Assoc. 2017, 52, 141-161. (In Korean) [CrossRef]

59. Guerra, E.; Dong, X.; Kondo, M. Do Denser Neighborhoods Have Safer Streets? Population Density and Traffic Safety in the Philadelphia Region. J. Plan. Educ. Res. 2019. [CrossRef]

60. Dumbaugh, E.; Li, W. Designing for the safety of pedestrians, cyclists, and motorists in urban environments. J. Am. Plan. Assoc. 2010, 77, 69-88. [CrossRef]

61. Huang, H.; Abdel-Aty, M.A.; Darwiche, A.L. County-level crash risk analysis in Florida: Bayesian spatial modeling. Transp. Res. Rec. 2010, 2148, 27-37. [CrossRef]

62. Jermprapai, K.; Srinivasan, S. Planning-level model for assessing pedestrian safety. Transp. Res. Rec. 2014, 2464, 109-117. [CrossRef]

63. Pulugurtha, S.S.; Duddu, V.R.; Kotagiri, Y. Traffic analysis zone level crash estimation models based on land use characteristics. Accid. Anal. Prev. 2013, 50, 678-687. [CrossRef] [PubMed]

64. Wier, M.; Weintraub, J.; Humphreys, E.H.; Seto, E.; Bhatia, R. An area-level model of vehicle-pedestrian injury collisions with implications for land use and transportation planning. Accid. Anal. Prev. 2009, 41, 137-145. [CrossRef] [PubMed]

65. Traffic Accident Analysis System (TAAS). Available online: http://taas.koroad.or.kr/gis/mcm/mcl/initMap. do?menuId=GIS_GMP_STS_RSN (accessed on 12 June 2019). (In Korean)

66. Seoul Open Data Plaza. Available online: http://data.seoul.go.kr/dataList/datasetList.do (accessed on 3 July 2019). (In Korean) 
67. Road Name Address Guidance System. Available online: http://www.juso.go.kr/addrlink/addressBuildDevNew. do?menu=mainJusoLayer (accessed on 14 June 2019). (In Korean)

68. Seoul Urban Planning Portal. Available online: http://urban.seoul.go.kr/4DUPIS/index.do (accessed on 12 June 2019). (In Korean)

69. National Spatial Data Infrastructure Portal. Available online: http://openapi.nsdi.go.kr/nsdi/eios/ServiceDetail. do?svcSe=F\&svcId=F010 (accessed on 13 June 2019). (In Korean)

70. Open Data Portal. Available online: https://www.data.go.kr/search/index.do (accessed on 14 June 2019). (In Korean)

71. Korean Statistical Information Service. Available online: http://kosis.kr/statisticsList/statisticsListIndex.do? menuId=M_01_01\&vwcd=MT_ZTITLE\&parmTabId=M_01_01 (accessed on 15 June 2019). (In Korean).

72. Diez-Roux, A.V. Bringing context back into epidemiology: Variables and fallacies in multilevel analysis. Am. J. Public Health 1998, 88, 216-222. [CrossRef] [PubMed]

73. Kim, D.-G.; Lee, Y.; Washington, S.; Choi, K. Modeling crash outcome probabilities at rural intersections: Application of hierarchical binomial logistic models. Accid. Anal. Prev. 2007, 39, 125-134. [CrossRef]

74. Snijders, T.A.; Bosker, R.J. Multilevel Analysis: An Introduction to Basic and Advanced Multilevel Modeling, 2nd ed.; Sage: London, UK, 2011.

75. Raudenbush, S.W. Hierarchical Linear Models: Applications and Data Analysis Methods; Sage: London, UK, 2002.

76. Wang, H.; Guo, X.-H.; Jia, Z.-W.; Li, H.-K.; Liang, Z.-G.; Li, K.-C.; He, Q. Multilevel binomial logistic prediction model for malignant pulmonary nodules based on texture features of CT image. Eur. J. Radiol. 2010, 74, 124-129. [CrossRef]

77. Demetriades, D.; Murray, J.; Martin, M.; Velmahos, G.; Salim, A.; Alo, K.; Rhee, P. Pedestrians injured by automobiles: Relationship of age to injury type and severity. J. Am. Coll. Surg. 2004, 199, 382-387. [CrossRef]

78. Prato, C.G.; Kaplan, S.; Patrier, A.; Rasmussen, T.K. Considering built environment and spatial correlation in modelling injury severity for pedestrian crashes. In Proceedings of the 96th Annual Meeting of the Transportation Research Board, Washington, DC, USA, 8-12 January 2017.

79. Jang, J.; Choi, J.; Kim, T. Analyzing Driving Environment Effects on Severity of Elderly Driver's Traffic Accidents. J. Transp. Res. 2017, 24, 79-94. (In Korean) [CrossRef]

80. Song, K. Seeking for a Policy and Implications for Creating a Safe Transportation Environment for Elderly Drivers in Gyeongnam. Gyeongnam Inst. 2014, 2014-16, 1-12. (In Korean)

81. Guo, R.; Xin, C.; Lin, P.-S.; Kourtellis, A. Mixed effects logistic model to address demographics and neighborhood environment on pedestrian injury severity. Transp. Res. Rec. 2017, 2659, 174-181. [CrossRef]

82. Arbogast, H.; Patao, M.; Demeter, N.; Bachman, S.; Devietti, E.; Upperman, J.S.; Burke, R.V. The Effectiveness of Installing a Speed Hump in Reducing Motor Vehicle Accidents Involving Pedestrians under the Age of 21. J. Transp. Health 2018, 8, 30-34. [CrossRef]

83. Rothman, L.; Macpherson, A.; Buliung, R.; Macarthur, C.; To, T.; Larsen, K.; Howard, A. Installation of speed humps and pedestrian-motor vehicle collisions in Toronto, Canada: A quasi-experimental study. BMC Public Health 2015, 15, 774. [CrossRef] [PubMed]

84. Korea Consumer Agency. Safety Survey of Speed Humps; Korea Consumer Agency: Chungcheongbuk-do, Korea, 2015. (In Korean)

85. Ministry of Government Legislation (Korea). Rules for the Designation and Management of Safety Zones for Children, the Elderly and the Disabled. Available online: https://www.moleg.go.kr/index.es?sid=a1 (accessed on 30 October 2019). (In Korean)

86. Kwon, J.; Park, S. A Study on Association between Pedestrian Traffic Accidents and Built Environment for Safe Routes to School: Using a Spatial Regression Model. J. Korean Reg. Dev. Assoc. 2018, 30, 75-96. (In Korean)

87. Hong, D.; Park, J.; Lim, J. Methods to Enhance Traffic Safety for Vulnerable Road Users. J. Transp. Res. 2018, 18-12, 1-228. (In Korean)

88. Ministry of Government Legislation (Korea). Act on Promotion of the Transportation Convenience of Mobility Disadvantaged Persons. Available online: https://http://www.law.go.kr/engLsSc.do?tabMenuId=tab45\& query $=$ act $\% 20$ on $\% 20$ promotion $\% 20$ of $\% 20$ the $\% 20$ transportation\# (accessed on 30 October 2019). (In Korean) 
89. Seo, J.; Lee, S. A Study on the Physical Environmental Factors Influencing Pedestrian Traffic Accidents in Seoul, Korea: Focused on the 2014 TAAS Data. J. Korea Plan. Assoc. 2016, 51, 197-216. (In Korean) [CrossRef]

90. Yoon, J.; Lee, S. Analysis of Pedestrian Traffic Accident Factors around the Exclusive Median Bus Lane Station Area: Focused on TAAS (2014-2016) Data in Seoul, Korea. J. Korea Plan. Assoc. 2018, 53, $123-142$. (In Korean) [CrossRef]

(C) 2020 by the authors. Licensee MDPI, Basel, Switzerland. This article is an open access article distributed under the terms and conditions of the Creative Commons Attribution (CC BY) license (http://creativecommons.org/licenses/by/4.0/). 